\title{
Las (des)ilusiones del posmodernismo
}

\author{
Jaime Osorio*
}

\begin{abstract}
Resumen
En tanto corriente filosófica el posmodernismo ganó una rápida legitimidad por su corrosiva crítica a fundamentos de la modernidad, las que considera agotadas, tales como la confianza en la ciencia como medio para conocer y organizar la vida social, la historia como un proceso que tiende al progreso material y social, y al sujeto como encarnación de metas trascendentales. En lo que sigue se critican algunos núcleos de la propuesta filosófica-epistémica posmoderna. Si bien son cuestionables muchas de las posiciones del positivismo-empirista, principal heredero de la modernidad científica, que terminó erigiéndose en "el enfoque científico", no es el posmodernismo la única y ni mucho menos la mejor base para sustentar tales cuestionamientos.
\end{abstract}

Palabras clave: Posmodernismo, totalidad, desconstrucción, modernidad

\begin{abstract}
As a philosophical tendency postmodernism rapidly gain legitimacy for its corrosive critics to fundaments of modernity, witch considers extinct, such as the trust in science as a way to know and organize life, history as a process of material and social progress, and the subject as an incarnation of transcendental goals. In this essay we critique some of the nucleus of the philosophic-epistemic proposals of postmodernism. If it is questionable that many of the positions of the positivism-empiric, main heiress of the scientific modernity that ended rising in the "scientific paradigm", postmodernism is not the only, and nevertheless the best stand to sustain such critics.
\end{abstract}

Key words: Postmodernism, totality, deconstruction, modernity

\footnotetext{
Departamento de Relaciones Sociales. Profesor de la Universidad Autónoma Metropolitana. Unidad Xochimilco. josorio@correo.xoc.uam.mx.
} 


\section{De los tiempos: teoría desde la derrota}

Antes de entrar propiamente en materia parece conveniente una breve contextualización. No es un asunto irrelevante el hecho que el florecimiento y auge inicial del posmodernismo en Europa, que puede ubicarse en los años setenta del siglo XX, sea coincidente con los tiempos de inicio del proyecto reestructurador de la economía y de la política a nivel mundial, de la mano del gran capital internacional, proceso conocido vulgarmente como globalización, periodo que contempla el derrumbe del socialismo "realmente existente", la tercera ola de la democratización liberal en la propuesta de Huntington y las formulaciones del "fin de la historia" de Fukuyama. Hay algo más que pura coincidencia y contingencia en la simultaneidad de estos procesos.

Tras afirmaciones como que "el gran relato ha perdido su credibilidad, sea cual sea el modo de unificación que se le haya asignado: relato especulativo, relato de emancipación"1, JeanFrancois Lyotard ubica al posmodernismo a lo menos en una posición escéptica frente a los planteamientos que postulan el cambio y la transformación social. Por ello Daniel Bensaid señala que "el rechazo posmoderno de los grandes relatos no implica solamente una crítica legítima a las ilusiones del progreso asociadas al despotismo de la razón instrumental. Significa también una de-construcción de la historicidad y un culto a lo inmediato, lo efimero, lo descartable, donde proyectos de mediano plazo no tienen más cabida" ${ }^{2}$.

El desencanto de una amplia generación de intelectuales ubicados en un espectro amplio de posiciones de izquierda, trotskistas, maoístas y libertarios en general, luego de la invasión soviética que puso fin a la Primavera de Praga, en Checoslovaquia,

Jean-Francois Lyotard, La condición posmoderna. Cátedra, Madrid, 1994, p. 73.

2 Daniel Bensaid, "Teoremas de la resistencia a los tiempos que corren", en Memoria n. 190, México, diciembre de 2004, p. 34, (subr. JO). Bensaid define al `mediano plazo` como el tiempo político por excelencia. Por ello agrega que "en la conjunción de los tiempos sociales desajustados, la temporalidad política es precisamente la del mediano plazo, entre el instante fugitivo y la eternidad inalcanzable". Ibidem. 
y de las revueltas del mayo francés de 1968, tuvo consecuencias teóricas y políticas que acentuaron el desencanto de esa generación con el socialismo en la Unión Soviética y Europa del Este, así como su escepticismo frente a la idea de la revolución, propiciando posiciones que afluirán en la gestación del planteamiento de los llamados "nuevos filósofos" y del posmodernismo.

En referencia a Francia en particular, Alex Callinicos señala que "la odisea política de la generación de 1968 es crucial para entender la difundida aceptación de la idea de una época posmoderna en los años ochentas. Es ésta la década en que los radicales de los años sesenta y setenta (...) habían perdido toda esperanza en el triunfo de una revolución socialista y a menudo habían dejado de creer incluso que una revolución semejante fuese desea$\mathrm{ble}^{\prime \prime 3}$.

Procesos con iguales consecuencias tienden a producirse en América Latina. Luego de la gran ebullición política y prolífica producción teórica que siguió al triunfo de la Revolución Cubana y que se prolonga hasta el fin del gobierno de Salvador Allende en Chile (1970-1973), las violentas políticas de contrainsurgencia que se desatan en la región, y en algunos países desde antes del golpe militar en Chile, dan inicio a un periodo de reflujo teórico que sólo comenzará a revertirse hacia fines de los años ochenta.

Desde esta perspectiva, tanto el posmodernismo, que se gesta en Europa, particularmente en Francia, así como las formulaciones en los años setentas y ochentas en América Latina en torno, por ejemplo, a los movimientos sociales y la sociedad civil, van a estar signadas como reflexiones que emergen bajo el peso y el clima que propicia la derrota.

Entre la represión inicial y el control posterior, en la academia latinoamericana tiende a hacerse sentido común la idea que los cuerpos teóricos que se abren al análisis de las revoluciones

\footnotetext{
En Contra el posmodernismo, El Áncora Editores, Bogotá, 1998, p. 316.
} 
sociales (y de la dominación y explotación, referencias que nos conducen sin muchos problemas al marxismo) deben ser abandonados o relegados. Ello va a tener una expresión no sólo teórica sino también política: desde un contexto en el que predominaba la idea de que el cambio societal y la revolución eran posibles, se pasa a otro en que se reclama el "realismo político", que no es más que la asunción que no hay cambio de fondo factible y que sólo queda convivir con un orden social que alguna vez se creyó poder superar. Para fines de los ochenta, y en los noventas, el terreno se encuentra apto para que al arribo del posmodernismo a América Latina, vía la academia europea y estadounidense, éste se expanda con rapidez.

En este clima asistimos a un acelerado cambio en los referentes teóricos, con la presencia de muchos más interlocutores teóricos que los aquí considerados, y con perspectivas políticas diversas. La emergencia de nuevos "temas", muchos de ellos de relevancia, no pudo sustraerse al abandono de "viejas" teorías rebasadas por los nuevos tiempos, con lo cual las nuevas formulaciones aparecían como el resultado de una verdadera revolución científica, un nuevo estadío del conocimiento. Así, del sistema mundial capitalista se pasará a hablar de la globalización; de economías centrales e imperialistas, a una noción de imperio, sin centro, dislocado y desterritorializado; de las clases sociales, a los movimientos sociales, la sociedad civil y a nuevos y viejos "actores"; de los debates sobre el poder y el Estado, a los análisis de las transiciones y a los estudios electorales; de la dominación, a la gobernabilidad; de la estructura, a lo contingente, a lo efímero, a un mundo social sin condensaciones y sin relaciones sociales, a lo sumo con redes. Del estudio de "una época (...) a través de sus manifestaciones -sus obras- y poner al descubierto las raíces sociales de esas formas simbólicas" ${ }^{\prime 4}$, a un pastiche cultural considerado interdisciplinario, porque toma un poco de todo, en

4 Carlos Altamirano (director), Términos críticos de la sociología de la cultura, Paidós, Buenos Aires, 2002, p. XII. La cita indicaría la visión de Mannheim sobre los estudios culturales. 
la "epistemología del shopping" (como quien llena un carrito de supermercado), con un énfasis por "la gracia social, el ritmo y los pasos que moldean la danza de la vida" ${ }^{5}$.

Este "pensar desde la derrota" propiciará la extraña convivencia posterior de posmodernos con planteamientos teóricos y políticos inmovilistas, junto a otros que se reclaman de izquierda o progresistas, casi todos abrevando en lo fundamental de Nietszche, Heidegger, Derridá o Foucault, con lo cual se produce una interesante disputa interpretativa sobre éstos autores, que se constituyen en los referentes centrales en el discurso posmoderno.

\section{Un metarrelato que destaca el fin de los grandes relatos}

Fue desde un escrito de Lyotard que el posmodernismo proclamó alguna de sus certezas, sintetizadas en la idea del fin de los grandes relatos y de toda formulación teórica que buscara una explicación totalizante de la historia, de la modernidad (y del capitalismo) ${ }^{6}$. El señalamiento de Lyotard, en contra de la razón instrumental de las ciencias y su idea de progreso, encontraba razones en hechos conocidos y de alta sensibilidad, sea en la irracionalidad de la experiencia nazi o en las prácticas del capital en su entorno ambiental. Su posición suponía dar vuelta la página en cómo reflexionar y en los hechos una propuesta de reiniciar el camino. Más allá de esta pretensión fundante, son sus propuestas para hacer frente a los males señalados los que consideramos problemáticos.

La crítica a los grandes relatos significaba en los hechos reclamar la centralidad de un nuevo metarrelato ${ }^{7}$, aquel que declara

\footnotetext{
Néstor García Canclini, “De cómo Clifford Geertz y Pierre Bourdieu llegaron al exilio", en Diferentes, desiguales y desconectados. Mapas de la interculturalidad. Gedisa, Barcelona, 2006.

6 Jean-Francois Lyotard, La condición posmoderna. Op. cit.., obra publicada en francés en 1979.

7 El propio Lyotard lo señala: "los grandes relatos se han tornado poco viables. Estamos tentados de creer, pues, que hay un gran relato de la declinación de los grandes relatos.". En La posmodernidad. Gedisa, Barcelona, sexta reedición, 1999, p. 40. (subrayado. JO)
} 
“(al) pequeño relato (...) como la forma por excelencia que toma la invención imaginativa, y, desde luego, la ciencia" ${ }^{\prime 8}$. Lo que se ponía en cuestión no era sólo la idea de un progreso en el devenir de la historia, señalada también desde otras vertientes. En el fondo fue la razón en tanto capacidad de buscar explicaciones del mundo (social) la que se puso en entredicho. Con ello una nueva versión del irracionalismo epistemológico tomaba forma?

El reclamo al abandono de pretensiones teóricas generales, de toda perspectiva holística, dejó a las ciencias como el receptáculo de reflexiones fragmentarias y contingentes. Lo singular y lo diverso pasaron a constituir el criterio de demarcación de los objetos de investigación. Con ello se propició una suerte de reificación de la pedacería societal.

El manifiesto posmoderno encontró seguidores en un campo mucho más amplio que aquellos que se reconocen filosóficamente con este enfoque. De manera gradual, temas relevados por el posmodernismo y olvidados o relegados con anterioridad, como el de las identidades, el multiculturalismo, la pluralidad de movimientos sociales, etc., así como diversas nuevas categorías (entre las más socorridas, desconstrucción, textualidad, juegos de lenguaje, significantes, significados, etc.), se fueron convirtiendo en vocabulario común en la academia. En una franja más restringida, sus planteamientos filosóficos y los del desconstruccionismo derridaniano pasaron a fundamentar posiciones consistentes ${ }^{10}$.

\footnotetext{
Jean-Francois Lyotard, La condición posmoderna, Op. cit., p. 109

9 Entre las posturas irracionalistas radicales "podríamos citar a los sofistas. Entre ellos se generalizan y extienden, como actitudes intelectuales, tanto el relativismo (no hay verdad absoluta) como el escepticismo (si hay verdad absoluta, es imposible conocerla) (...)". En Jacobo Muñoz y Julián Velarde (edts), Compendio de epistemología. Op. cit., p. 365. Allí se establece la distinción entre el irracionalismo epistemológico, que postula que "la razón no puede conocer lo real (o sólo en parte)", por lo que "a lo real se accede por vía de otros conocimientos", diferentes a los de la razón, como la intuición o el corazón, posición en donde se ubicaría el posmodernismo, del irracionalismo metafísico, que señala "el carácter absurdo e insensato de la realidad". Op. cit. pp. 365-367.

10 Es frecuente que se ubique a Jacques Derrida entre los autores "que han insistido en la necesidad de salir de la tradición filosófica moderna", por lo que sus posiciones "resultan afines a la sensibilidad posmoderna". Nicola Abbagnano, Diccionario de Filosofía, Fondo de Cultura Económica, México, cuarta edición, 2004, p. 839.
} 


\section{El malestar con la totalidad}

Una de las derivaciones del reclamo posmoderno al fin de los grandes relatos remite al rechazo a la noción de totalidad ${ }^{11}$, generalmente asociada a "todo lo que existe", con lo cual se aproxima más bien a la de completud formulada por Morin ${ }^{12}$. En sus versiones más extremas, enfatizar la necesidad de la totalidad es sinónimo de totalitarismo, visión en lo que el posmodernismo comparte posiciones con el positivismo. Pero ¿qué significa aprehender la realidad como totalidad? Dicho de manera breve, dar cuenta de lo que articula y estructura la vida social, de aquello que la organiza y jerarquiza y que termina otorgándole sentido en alguna temporalidad específica. No más, pero tampoco menos. En nuestro tiempo, ello se sintetiza en la lógica del capital y su afán de valorización, proceso que marca de manara indeleble las relaciones humanas y el mundo institucional que las acompaña.

Esa lógica es prioritariamente un campo de relaciones sociales que atraviesan la producción y la reproducción social, conformando un entramado que impone su signo sobre toda la vida en sociedad. El afán de valorización del capital organiza la vida material y espiritual: las formas del trabajo y la vida sexual, las guerras y las subjetividades, el poder y la rebelión, por mencionar algunos grandes campos y temas, los que alcanzan mayor inteligibilidad en esa órbita relacional. El conocimiento de fragmentos y parcelas y de sus singularidades será superior entonces si se los ubica en el terreno de las relaciones en que ellos se integran y articulan: un mundo social regido por la lógica del capital.

La mistificación posmodernista de los fragmentos, expresada en la forma como aborda la diversidad cultural, la segmentación y dislocación del poder, o las identidades fragmentadas, nos

11 En mi libro Fundamentos del análisis social. La realidad y su conocimiento, Fondo de Cultura Económica-UAM, México, 2001, cap. I, se puede encontrar un mayor desarrollo de este tema.

12 Edgar Morin, Introducción al pensamiento complejo, Gedisa, Barcelona, segunda reimpresión, 1998. 
deja en el terreno de la fetichización, de la ausencia de relaciones en un mundo capitalista que opera, por el contrario, como totalidad, fuertemente articulada, sea en materia de poder político, económico e ideológico. No es razonable desconocer el sinfin de cadenas productivas, segmentadas y repartidas por el mundo por el capital industrial; la desterritorialización propiciada por el capital financiero, por mencionar algunos asuntos relevantes. Pero esta reflexión peca de unilateralidad, porque queda atrapada en la contingencia desarticuladora, incapaz de ver su contracara y el núcleo que la propicia: la férrea centralización del poder político y económico en tiempos de mundialización ${ }^{13}$. Por ello, un asunto clave en la etapa actual es explicar porqué un sistema tan centralizado reclama hoy de tanta descentralización en su despliegue y funcionamiento.

\section{Realidad y verdad como no-problemas epistémicos}

Tras su emergencia con un perfil crítico, el descontruccionismo, que nace en Francia, arriba a la academia de los Estados Unidos en los años ochenta y sienta sus reales en los departamentos de Letras, dando vuelo a los cultural studies, alejados de la propuesta anglosajona sobre los estudios culturales recorrida por Raymond Williams, E.P. Thompson, Terry Eagleton, y proseguida por Fredric Jameson y Slavoj Zizek ${ }^{14}$, en donde la cultura no es ajena a un tiempo histórico y a la reproducción y contradicciones de la vida social. Importa destacar que ese paso marcará un giro en la forma como es asumida la propuesta teórica de Derrida, "convirtiéndose (...) de una corriente filosófica en, básicamente, un método de análisis textual"15.

13 Véase al respecto de Jaime Osorio, El Estado en el centro de la mundialización. La sociedad civil y el asunto del poder. Fondo de Cultura Económica, México, 2004.

14 Y que de diversas maneras se hace cargo de lo realizado por Gramsci, Lukács, Benjamin, Adorno, Sartre y Marcuse, entre otros.

15 "Desconstruccionismo", Elías José Palti, en el libro Términos críticos de sociología de la cultura, Carlos Altamirano (director). Paidós, Buenos Aires, 2002, p. 63. 
Muy rápidamente el desconstruccionismo se extendió a diversos territorios de las ciencias sociales. Los vulgarizadores, con todas sus letras, hicieron suya la afirmación derridaniana que "no hay (nada) fuera de(l) texto" ${ }^{16}$, dando vida a lo que se ha calificado como "imperialismo textual" o "pantextualismo": los discursos científicos pueden ser asumidos como un discurso más, sin referencia a nada ajeno a ellos mismos, ignorando "aquello que desborda al discurso (...), aquello que no puede ser reducido al "texto", aunque dependa del él para hacerse aparente"17. En definitiva, desconocer "una teoría que reconozca alguna diferencia entre lo real y el discurso"18.

En la base de esta postulación se encuentra un planteamiento particular respecto a la relación entre discurso y realidad, que devalúa filosóficamente la significación de la realidad. El camino podría describirse así: el posmodernismo establece una distinción entre independencia causal, por ejemplo, que las montañas existen con independencia de que "la gente tuviera en la mente la idea de montaña o en su lenguaje la palabra montaña", al fin que "una de las verdades obvias acerca de las montañas es que estaban allí antes de que empezáramos a hablar de ellas"19, y causación representacional, en donde "no tiene objeto preguntar si existen realmente montañas o si es sólo que nos resulta conveniente hablar de montañas", ya que "carece de objeto preguntar si la realidad es independiente de nuestro modo de hablar de ella"20, o de nuestras representaciones. Y "carece de objeto" porque no tenemos otra forma de referirnos a la realidad más que con lenguajes y algún sistema de representación. Y como entre las palabras o representaciones y

\footnotetext{
16 Jacques Derrida, De la gramatología, Siglo XXI, México, 1986.

17 Eduardo Grüner, "El retorno de la teoría crítica de la cultura: una introducción alegórica a Jameson y Zizek", en Fredric Jameson y Slavoj Zizek, Estudios Culturales. Reflexiones sobre el multiculturalismo. Paidós, Buenos Aires, tercera reimpresión, 2005, p. 49 .

Eduardo Grüner, Op. cit., p. 48.

Richard Rorty, Verdad y progreso, Paidós, Barcelona, 2000, p.100.

20 R. Rorty, Verdad y progreso, Op. cit., p. 100 (Subr. JO).
} 
las cosas no hay ningún "pegamento metafísico", nada nos asegura que existe algo más allá de las palabras y las representaciones ${ }^{21}$.

Lo anterior, al decir de Eagleton , constituye "un retorno regresivo al Wittgenstein del Tractatus Logico-Philosophicus, donde sostiene que dado que nuestro lenguaje nos "da" el mundo, no puede simultáneamente comentar su relación con él"22.

Pero si no hay realidad ajena al lenguaje posible de conocer, la propia idea de verdad queda como un asunto "no epistémico", o bien un no-problema. Por ello Rorty señala que "si recojo lo que algunos filósofos han dicho sobre la verdad, es con la esperanza de desalentar al que se siga prestando atención a este tema más bien estéril”23.

\section{Las ciencias sociales y la filosofía como discursos literarios}

Una consecuencia de este proceso ha sido la literaturización del discurso en ciencias sociales, que al hacerse autorreferencial, sin las constricciones de un "algo" más allá al texto, ha propiciado el desdibujamiento de las fronteras entre literatura y ciencias y entre literatura y filosofía ${ }^{24}$. Derrida fue claro en su distancia frente a este tipo de posiciones. Tras excusarse por tener que "hablar un poco brutalmente", señaló: "jamás traté de confundir literatura y filosofía o de reducir la filosofía a la literatura", en respuesta a posturas en tal sentido en la academia estadounidense y de Rorty en particular ${ }^{25}$.

En esta lógica, siguiendo a Wittgenstein, Rorty se pregunta:" ¿has encontrado algún modo de meterte entre el lenguaje y su objeto...?". Verdad y progreso, Op. cit., p. 124.

22 Terry Eagleton, Las ilusiones del posmodernismo, Paidós, Buenos Aires, segunda reimpresión 2004, p.67. Eagleton señala que "el Wittgenstein de los últimos tiempos acaba por renunciar a esa perspectiva monística..", y dejó de pensar el "lenguaje como una totalidad" considerando "actos discursivos (...) que se relacionan con el mundo", proveyendo éste "la razón para aquellos". Op. cit., p. 67.

23 R. Rorty, Verdad y progreso, Op. cit., p. 23.

24 Una defensa de esta postura puede verse en Richard Rorty, Ensayos sobre Heidegger y otros pensadores contemporáneos, Paidós, Barcelona, 1993, Segunda Parte, pp. 125-182.

25 Véase la postura de ambos en Desconstrucción y pragmatismo. Simon Critchley et. al. Compilación de Chantal Mouffe. Paidós, Buenos Aires, 1998. 
No desconocemos que la filosofía puede hacer uso de recursos literarios y que la literatura de recursos filosóficos. Allí está la producción de Jorge Luis Borges para ponerlo de manifiesto. Pero esto no supone desconocer las particularidades de cada quehacer. En este sentido queda claro que, en strictu sensu, Borges no es filósofo ${ }^{26}$.

En este contexto, desde la lógica del posmodernismo desconstruccionista, la teoría pierde significación. Importa más la estética del discurso que la rigurosidad epistémica y conceptual, asuntos estos últimos que son asumidos como barreras a la libertad creativa. El discurso científico no es más que un "juego de lenguaje".

\section{La devaluación de la filosofía}

El quehacer académico se realiza en el contexto de viejos problemas que atraviesan a las ciencias sociales, renovados y reciclados por el auge posmoderno-desconstruccionista. Tal es lo que acontece respecto a la antigua y conflictiva relación entre ciencias sociales y filosofía.

Desde el posmodernismo esta relación tiende a perder significación ya que desconoce la especificidad del discurso de las ciencias frente a cualquier otro discurso ${ }^{27}$, lo que termina por anular ficticiamente aquel conflicto, al eliminar a uno de los elementos en tensión. Por estas vías el posmodernismo ha desvirtuado el sentido de la filosofía, en tanto una práctica de la razón orientada al saber ${ }^{28}$. El propio quehacer filosófico, desde una postura filosófica, termina siendo devaluado.

26 No desconozco los planteamientos que señalan que en general todos los hombres (como especie) somos filósofos. Pero esta afirmación, tras su aparente generosidad y benevolencia, termina por diluir la especificidad de la filosofía. De igual modo podría afirmarse que todos somos poetas, físicos o músicos.

27 Para Rorty, "la ruptura de la distinción entre filosofía y literatura es esencial para la desconstrucción", ya que su filosofía lleva "en la dirección de 'una textualidad general indiferenciada ."En Ensayos sobre Heidegger y otros pensadores contemporáneos. Op. Cit., p. 125 (subr. original).

28 Así, de acuerdo a "la definición que aparece en el Eutidemo platónico: la filosofía es el uso del saber para ventaja del hombre". En Nicola Abbagnano, Diccionario de filosofía, Fondo de Cultura Económica, México, cuarta edición, 2004, p. 485. 
Todo lo anterior no implica que el posmodernismo no establezca una plataforma filosófica. Apoyándose en Wittgenstein, niega "la posibilidad de un metadiscurso omnicomprensivo"; "su ruptura con la razón totalizante se presenta como un "adios" a las grandes narraciones -les grands récits- (emancipación de la humanidad, por ejemplo), por una parte, y al fundamentalismo por otra"; "el grand récit de la filosofía, la ciencia...ha dejado de ocupar el papel prioritario y ha dejado de ser el principio legitimador ${ }^{\prime 2}$.

La resignificación del pequeño relato y de la fragmentación, despreciando toda búsqueda de explicaciones generales y de la noción filosófica de totalidad; el rechazo a las condensaciones estructurales y a la idea de continuidad (y con ello de proceso) en la historia, lleva a destacar sólo las contingencias, las discontinuidades, lo incierto. Uno de los problemas del posmodernismo es la unilateralidad de su propuesta. No termina de comprender que contingencia, discontinuidad, parte, etc., constituyen expresiones de una realidad que necesariamente contiene la otra dimensión, que con esos términos se pretende negar, tales como necesidad, continuidad, totalidad, etc.

¿En qué sentido asumir en la vida social las manoseadas ideas de que vivimos en la incertidumbre o en la contingencia? ¿Cuál son su significación? Porque para millones de sujetos este mundo se mueve, en cuestiones centrales, con una gran certidumbre: saben con certeza que si no salen día a día a vender su capacidad de trabajo se mueren de hambre. Y que si no encuentran trabajo o encuentran un trabajo con salarios paupérrimos, como de manera creciente tiende a ocurrir, tendrán que realizar alguna otra actividad, como vender algo en la vía pública, ofrecer algún servicio en algún crucero (como limpiar cristales de autos), pedir limosna o robar. Las actividades pueden ser inciertas y contingentes, pero todas ellas derivan de una gran certeza.

29 Jacobo Muñoz y Julián Velarde, Compendio de epistemología, Op. cit., p. 369 
Temas como los hasta aquí expuestos ponen de manifiesto los equívocos de quienes suponen una tajante separación entre ciencia y filosofía, como en el caso de los positivistas ${ }^{30}$, pero también de quienes, como los posmodernos, terminan por diluir todo en simples "juegos de lenguaje", haciendo perder la especificidad de la filosofía y de las ciencias.

Desde esta perspectiva, no es un problema menor la ausencia de cursos de filosofía y en particular de epistemología en los programas de estudios de las carreras de ciencias sociales, tanto a nivel de licenciatura como de posgrado. Conocer los fundamentos filosóficos de las teorías permite poner al descubierto los supuestos sobre las cuales éstas se construyen, y nos otorgan mejores bases para comprender el horizonte de visibilidad que nos ofrecen, tanto en lo que privilegian e iluminan como problemas centrales, así como sobre los puntos ciegos que tienden a presentar.

\section{A modo de conclusión}

Poner de manifiesto asuntos como los aquí abordados no significa un rechazo de todo lo que determinada escuela o corriente filosófica produce y propone. Tampoco significa desconocer su legítimo papel y lugar en el mundo de las ideas en el campo académico. Este tipo de ejercicios debiera hacerse con todas las corriente teóricas y filosóficas. Ninguna debiera estar excluida del juicio de la razón. Pero asistimos a un clima de época académico en donde prevalece el "todo se vale", que bajo un manto de aparente respeto y tolerancia a lo diverso, constituye en realidad un fuerte signo de intolerancia (y de rechazo), por la vía de la indiferencia.

30 Para éstos, aún con mayor razón, hay que distanciarse de la metafísica para hacer ciencia. Pero mientras le cierran la puerta, ésta entra por la ventana de sus propuestas: así, la economía neoclásica o la teoría política del racional choice suponen en su construcción "naturalezas humanas" egoístas, racionalistas, calculadoras, etc. Que sepa, no aparece aún ningún gen en donde se deposite alguna de esas cualidades. Estamos así en la metafísica. 


\section{Bibliografía}

Abbagnano, Nicola (2004). Diccionario de Filosofía, Fondo de Cultura Económica, México, cuarta edición.

Altamirano, Carlos (2002). Términos críticos de la sociología de la cultura, Paidós, Buenos Aires.

Bensaid, Daniel (2004). "Teoremas de la resistencia a los tiempos que corren", en Memoria n. 190, México.

Callinicos, Alex (1998). Contra el posmodernismo. El Áncora Editores, Bogotá.

Derrida, Jacques (1986). De la gramatología, Siglo XXI, México.

, (1998). "Notas sobre desconstrucción y pragmatismo", en Mouffe, Chantal (compilación), Desconstrucción y pragmatismo. Paidós, Buenos Aires.

Eagleton, Terry (1997). Las ilusiones del posmodernismo, Paidós, Buenos Aires.

García Canclini, Néstor (2006). “De cómo Clifford Geertz y Pierre Bourdieu llegaron al exilio", en Diferentes, desiguales y desconectados. Mapa de la interculturalidad. Gedisa, Barcelona.

Hardt, Michael y Antonio Negri (2002). Imperio, Paidós, Buenos Aires.

Jameson, Fredric, y Slavoj Zizek (2005). Estudios Culturales. Reflexiones sobre el multiculturalismo. Paidós, Buenos Aires, tercera reimpresión.

Lyotard, Jean-Francois (1994). La condición posmoderna. Cátedra, Madrid.

Mouffe, Chantal (1998). Desconstrucción y pragmatismo. Paidós, Buenos Aires.

Muños, Jacobo y Julián Velarde (2002). Compendio de epistemología, Editorial Trotta, Madrid.

Osorio, Jaime, El Estado en el centro de la mundialización. La sociedad civil y el asunto del poder, Fondo de Cultura Económica, México, 2004.

Fundamentos del análisis social. La realidad social y su conocimiento. Fondo de Cultura Económica-UAM, México, 2001.

Palti, Elías José, Verdades y saberes del marxismo. Fondo de Cultura Económica, Buenos Aires, 2005.

Rorty, Richard, Ensayos sobre Heidegger y otros pensadores contemporáneos, Paidós Barcelona, 1993.

, Verdad y progreso, Paidós, Barcelona, 2000.

, "Notas sobre desconstrucción y pragmatismo", en Mouffe, Chantal (compilación), Desconstrucción y pragmatismo, Paidós, Buenos Aires, 1998. 